\title{
Non-stationary behavior of roof drainage systems
}

\author{
Martin Koláček ${ }^{1, *}$ \\ ${ }^{1}$ Tomas Bata University in Zlin, Faculty of Applied Informatics, Department of Automation and control Engineering, Nad Stranemi 4511, Zlin, \\ Czech Republic.
}

\begin{abstract}
This paper reports the non-stationary behavior of a roof drainage during experimental measurement in the climate simulator. Many buildings use a fully or partially flat roof where it is necessary to use the roof drainage. Thermal behavior of roof drainage is very important from the point of view of heat transfer and potential condensation. The placement of a roof drain slightly deteriorates thermal transmittance of the roof. This experiment evaluates roof drains in the specific climate simulator where thermal conditions were dynamically controlled in the specific temperature range. The measurement was performed for two types of roof drains. The first drainage is a simple single-shell and the second is doubleshell drainage. The results show the effect on the thermal transmittance of the roof section and also the minimal effect of condensation on the non-insulation part of the drainage. Both roof drains showed minimal deterioration of thermal transmittance of the roof construction.
\end{abstract}

\section{Introduction}

Drainage systems of roof areas are an important task in modern residential, industrial or commercial construction. The use of internal rainwater drains is very common not only for flat roofs. The roof drainage is important in term of the thermal insulation properties of the roof.

Some studies verify modification of the length of the downpipe and its impact on increasing the flowrate [5]. Roof drainage systems are designed to the size of the roof, the number of drains and also the estimated amount of water as is described in [4].

There are not so many studies that investigate the influence of roof drainage on the thermal parameters of the roof. However, there are standards to indicate requirements for surface indoor temperatures due to the possibility of condensation of water inside buildings as describes [1].

Many roof designs have exposed to heavy seasonal rain and designers need to take increased rainfall intensity. The roofs may be drained by two basic methods, towards the outer edges and into external gutters or towards internal gutters or drainage outlets within the main roof area [3]. Gutters can be blocked by hail or due to rainfall intensity. Therefore it is important to evaluate and to compare the width of the drainage. The requirements for the location of roof drains are described in $[7,6]$. Thermal transmittance describes the insulation capacity of a building structure. The roof drain slightly deteriorates the insulation properties of a building structure. Due to this fact, we try to evaluate the influence of roof drain in the roof.

Roof drain causes a thermal bridge through the roof structure. Such a construction may cause the surface temperature of the structure to fall below the dew point. Therefore it is important to measure surface temperature on the surface that is directly in contact with the outside environment.

In this paper, the thermal properties of the roof drainage will be investigated and the surface temperature will be measured on the critical parts of the roof drainage under the different climatic conditions.

\section{Methods}

The measurement was performed on the two types of roof drains. The inlet of the first drain is $212 \mathrm{~mm}$ wide and is formed by a one-sided layer. The second drainage has inlet $130 \mathrm{~mm}$ wide and the wall is double-shell. Both drains are used for a $100 \mathrm{~mm}$ drainage line. These roof drains were measured in specific measuring box which was installed in the calorimetric chamber. The thermal parameters of the measuring box are similar to the actual roof structure. The both drains were equipped with a 100 $\mathrm{mm}$ strong polystyrene for testing the thermal behavior. This allows for a view of the heat transfer towards the connected duct pipe and only the part of the inlet body, which usually adjoins with the ceiling concrete slab. The dimension of tested sample and roof of the box are described in Table 1.

Table 1 Dimensions of constructions

\begin{tabular}{|l|c|}
\hline \multicolumn{1}{|c|}{ Construction } & Surface $\left[\mathrm{m}^{2}\right]$ \\
\hline Roof of the box & 2,25 \\
\hline Single-shell roof drainage & 0,035 \\
\hline Double-shell roof drainage & 0,013 \\
\hline
\end{tabular}

* Corresponding author: kolacek@,fai.utb.cz 

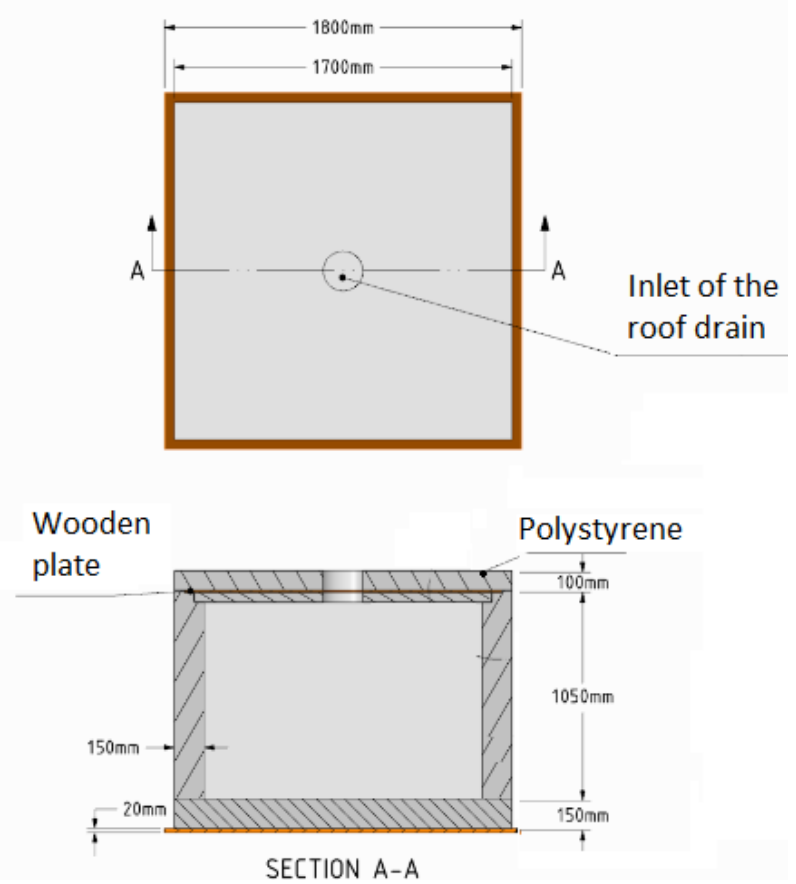

Figure 1 Measuring box where the roof drains were installed

Figure 1 shows dimensions of measuring box and position of the roof drainage.

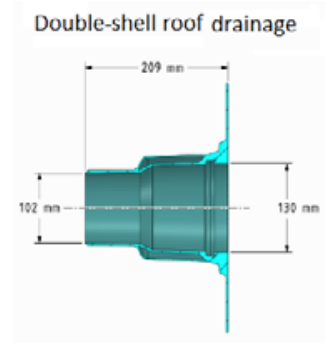

SECTION A-A

Single-shell roof drainage

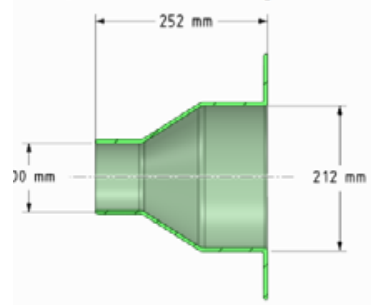

SECTION B-B
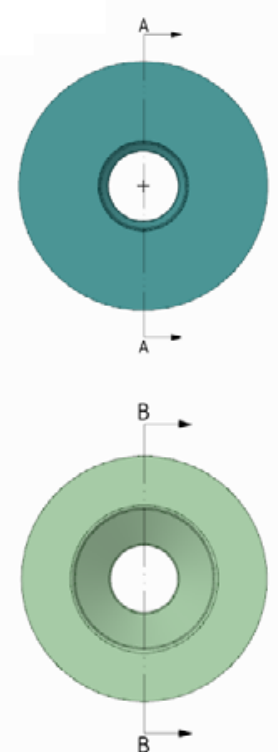

Figure 2 pictures of the roof drains

As can be seen in Figure 2 the roof drains have a different dimension of the inlet and different depth.

The calorimetric chamber is a device in which the climatic condition can be controlled in the specific temperature range from $-20{ }^{\circ} \mathrm{C}$ to $+50{ }^{\circ} \mathrm{C}$. Each of the roof drains was placed in the measuring box and was exposed to three climatic tests as described Table 2
Table 2 The conditions of thermal tests

\begin{tabular}{|c|c|c|}
\hline Test & $\begin{array}{c}\text { The air temperature } \\
\text { outside the box }\left[{ }^{\circ} \mathrm{C}\right]\end{array}$ & $\begin{array}{c}\text { The initial air } \\
\text { temperature inside the } \\
\text { box }\left[{ }^{\circ} \mathrm{C}\right]\end{array}$ \\
\hline 1 & 10 & 20 \\
\hline 2 & 0 & 20 \\
\hline 3 & -15 & 20 \\
\hline
\end{tabular}

The heating element regulated the air temperature inside the measuring box for all tests. The thermal performance of this device represented heat loss of the box. The cooling curve was measured by the insulating effect of the inlet at the time-varying non-stationary air temperature inside the box. The air temperature of the exterior was stable during each experiment because temperature fluctuations are minimal during the day in winter. The decrease of the air temperature inside the box on the warm side of the inlet is similar to that of the space heating operation in the space below the flat roof, it can be simulated by switching off the heater.

The thermal transmittance was calculated by equation (1):

$$
U=1 /\left(1 / h_{\mathrm{i}}+d / \lambda+1 / h_{e}\right)
$$

Where $U$ is the thermal transmittance $\left[\mathrm{W} \cdot \mathrm{m}^{-2} \cdot \mathrm{K}^{-1}\right.$ ]

$h_{\mathrm{i}} \quad$ the heat transfer coefficient on the inside of the structure $\left[\mathrm{W} \cdot \mathrm{m}^{-2} \cdot \mathrm{K}^{-1}\right]$

$h_{\mathrm{e}}$ the heat transfer coefficient on the exterior of the structure $\left[\mathrm{W} \cdot \mathrm{m}^{-2} \cdot \mathrm{K}^{-1}\right]$

$d \quad$ thickness of the structure [m]

$\lambda$ thermal conductivity coefficient $\left[\mathrm{W} . \mathrm{m}^{-}\right.$ $\left.{ }^{1} \cdot \mathrm{K}^{-1}\right]$

Het loss was calulated by equation (2)

$$
\phi=\Sigma(A \cdot U) \cdot\left(\Theta_{i}-\Theta_{e}\right)
$$

where $\phi$ is heat loss of heated space [W]

$A \quad$ surface of construction $\left[\mathrm{m}^{2}\right]$

$\Theta_{i} \quad$ internal temperature $\left[{ }^{\circ} \mathrm{C}\right]$

$\Theta_{e} \quad$ external temperature $\left[{ }^{\circ} \mathrm{C}\right]$

Table 3 Heat transfer coefficient

\begin{tabular}{|c|c|c|}
\hline \multirow{2}{*}{ Surface } & Construction & $\begin{array}{c}\text { Heat transfer } \\
\text { coefficient }\left[\mathrm{W} \cdot \mathrm{m}^{-2} \cdot \mathrm{K}^{-1}\right]\end{array}$ \\
\hline Exterior & Single-skinned & 25 \\
\hline Interior & wall & 7,7 \\
\cline { 2 - 3 } & roof & 10 \\
\cline { 2 - 3 } & floor & 5,9 \\
\hline
\end{tabular}


The thermal transmittance was calculated for the Czech Technical Standard - Thermal protection of buildings [1]. It was necessary to calculate the average thermal transmittance of the entire roof area with the roof drainage. The thermal transmittance of the roof drainage was established by heat loss of the object and the conversion to the given area.

\section{Results}

The non-stationary behavior of roof drains was measured for three climatic test for each roof drain. The heat loss were firstly measured for the measuring box without roof drainage in graphs is described as Insulation plate. The thermal transmittance of insulation plate was calculated to evaluate deterioration of heat transmission due to the implementation of roof drainage.

The thermal performance of heating source was tested under the different thermal condition of the measuring box. It was done three tests where the temperature conditions were stably maintained inside and outside the box and this corresponds to the heat performance. The chart directive indicates heat loss of the box without the drainage. Heat loss is $28,5 \mathrm{~W}$ for $10^{\circ} \mathrm{C}$ temperature difference. Application of single-shell drainage increased heat loss up to $32 \mathrm{~W}$ and for doubleshell up to $30 \mathrm{~W}$.

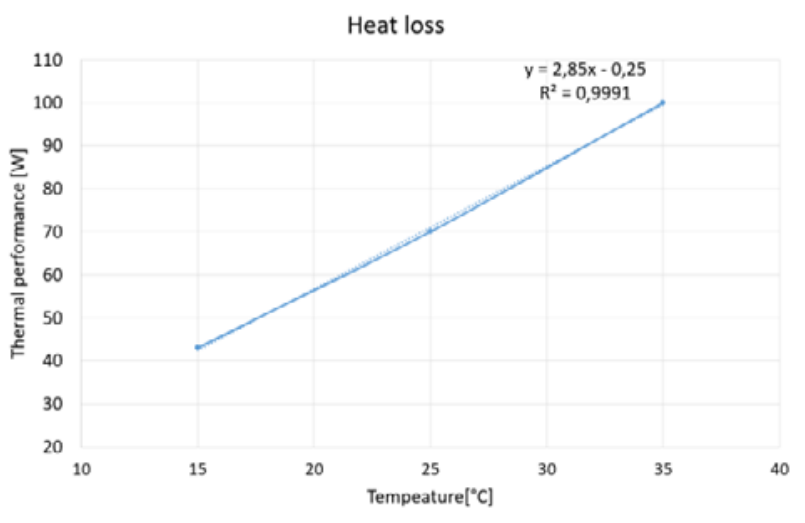

Figure 3 Heat loss of measuring box without roof drainage

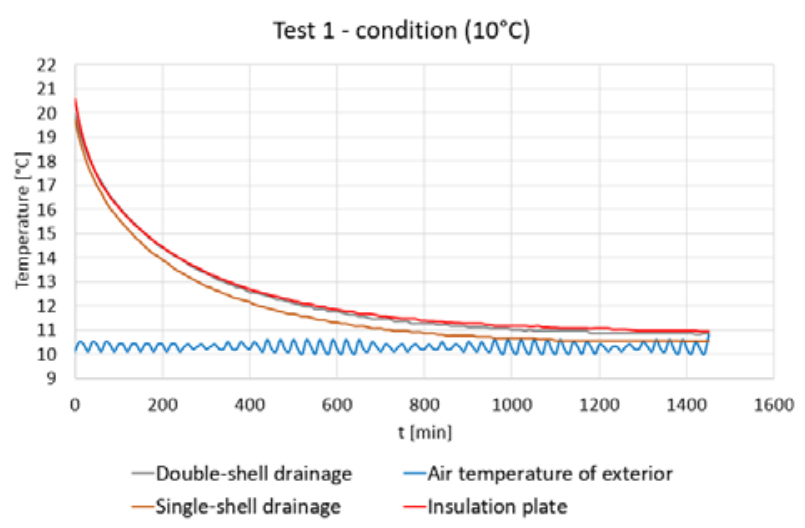

Figure 4 The cooling curve for the air temperature after the heater turrned inside the box, Thermal test 1, Exterior air temperature $10^{\circ} \mathrm{C}$
As can be seen in Figure 4, the air temperature decrease faster by using Single-shell drainage than the doubleshell drainage. The higher thermal transmittance of single-shell drainage caused faster cooling process inside the box.

Table 4 The results of the thermal transmittance

\begin{tabular}{|l|c|}
\hline $\begin{array}{l}\text { Thermal transmittance without } \\
\text { drainage }\end{array}$ & $0,257 \mathrm{~W} / \mathrm{m}^{2} \mathrm{~K}$ \\
\hline $\begin{array}{l}\text { Thermal transmittance with Single- } \\
\text { shell drainage }\end{array}$ & $0,318 \mathrm{~W} / \mathrm{m}^{2} \mathrm{~K}$ \\
\hline $\begin{array}{l}\text { Thermal transmittance with Double- } \\
\text { shell drainage }\end{array}$ & $0,296 \mathrm{~W} / \mathrm{m}^{2} \mathrm{~K}$ \\
\hline
\end{tabular}

The thermal transmittance is shown in Table 4. These values are related to the roof area of the box. The thermal transmittance is only reduced by $7 \%$. However, it is the value of the thermal transmittance of the entire roof structure. The results can be recalculated to the example of a flat roof of $100 \mathrm{~m}^{2}$. This roof should be drained using roof drains with corresponding thermal insulation compared to the insulation which was used in the measuring box. The total thermal transmittance of such a roof can be calculated. The single-shell drainage causes a deterioration of the thermal transmittance by $0,2 \%$ than the double-shell drainage. Comparison of the roof without roof drainage with single-shell drainage, a deterioration of the thermal transmittance is by $0,05 \%$ and for double-shell is only by $0,03 \%$.

A heat transfer area that does not have additional insulation is for single-shell drain $0,055 \mathrm{~m}^{2}$ and for double-shell drainage $0,045 \mathrm{~m}^{2}$. The surface temperature of this area was measured on the both roof drains. During the thermal test 3 , the surface temperature was 17 ${ }^{\circ} \mathrm{C}$ for single-shell drain and $17,6{ }^{\circ} \mathrm{C}$ for double-shell drainage, the exterior air temperature was $-15{ }^{\circ} \mathrm{C}$ and inside the box was $20{ }^{\circ} \mathrm{C}$. This experiment confirmed high insulation properties of the both roof drainage and the possibility of condensation is minimal at the surface of the drainage.

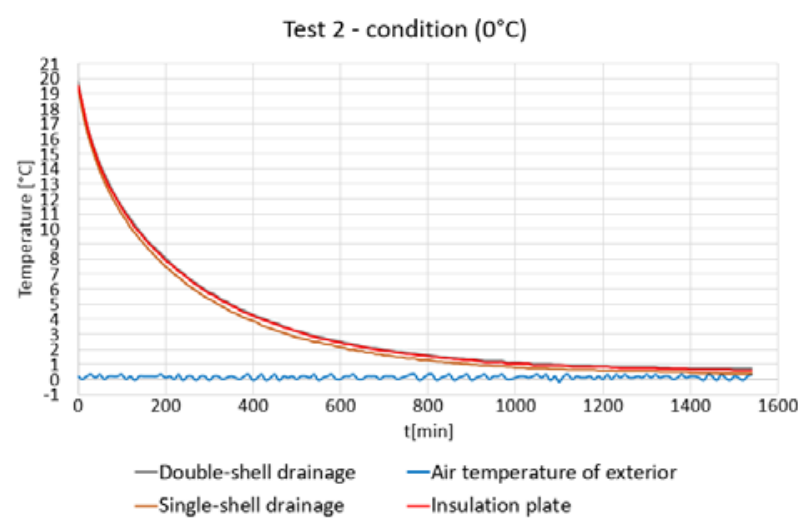

Figure 5 The cooling curve for the air temperature after the heater turrned inside the box, Thermal test 2, Exterior air temperature $0^{\circ} \mathrm{C}$ 


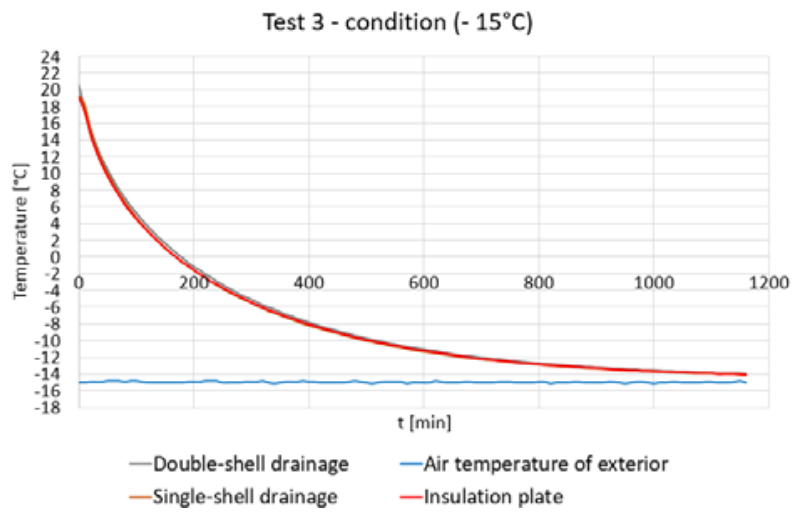

Figure 6 The cooling curve for the air temperature after the heater turrned inside the box, Thermal test 3, Exterior air temperature $-15^{\circ} \mathrm{C}$

Figure 5 and Figure 6 show minimal temperature differences between single and double-shell roof drainage. It is difficult to verify the cooling process of the box when the exterior air temperature is so low. Due to the minimal difference in the thermal transmittance of the roof drains.

\section{Conclusion}

The experiment was conducted to investigate the nonstationary behavior of the roof drainage system. These systems are used in flat roofs where can deteriorate thermal properties of the roofs and can cause condensation on the surface of the roof drain. The thermal transmittance was calculated for two types roof drains. These roof drains were tested under three different climatic conditions and were compared. The measurement confirmed minimal deterioration of thermal properties of the roof. The placement of the roof drain has a minimal effect on the deterioration of the thermal transmittance.

The difference between the roof drains is evident in cooling at an exterior air temperature $10{ }^{\circ} \mathrm{C}$. The surface temperatures were much higher than the dew point on the noninsulated part of the roof drain during the experimental test when the surrounding temperature was $-15^{\circ} \mathrm{C}$.

The temperature stratification through the roof drainage will be the subject of the future studies. These studies will be evaluated in simulation software.

\section{Acknowledgments}

This work was supported by the Ministry of Education. Youth and Sports of the Czech Republic within the National Sustainability Programme project No.LO1303(MSMT7778/2014), by the European Regional Development Fund under the project CEBIA-Tech No.CZ.1.02/2.1.00/03.0089 and also by the Internal Grant Agency of Tomas Bata University in Zlín under the project No. IGA/CebiaTech/2017/002.

\section{References}

1. Czech technical standard CSN 730540. Thermal protection of buildings - Part 2: Requirements (2011). Czech normalisation institute Prague.

2. Czech technical standard CSN EN 12831. Heating systems in buildings - Method for calculation of the design heat load (2005). Czech normalisation institute Prague.

3. HR Wallingford. Roof Drainage Systems. Tech Talk. Volume 9. (2012). Alianze Global Corporate and Speciaty AG.

4. Manual for the Design of Roof Drainage Systems. A guide to the use of European Standard BS EN 12056-3:2000. Report SR 620. (2003)

5. Arthur, S. and J. A. Swaffield. (2001). "Siphonic Roof Drainage System Analysis Utilising Unsteady Flow Theory." Building and Environment 36 (8): 939-948

6. Czech technical standard CSN EN 1253-2. Gullies for buildings - part 2: Roof drains and floor gullies without trap. (2016). Czech normalization institute Prague

7. Howard, C. Massey. Plumber's handbook. Revised Edition. Craftsman Book Company. (1998). Carlsbad. ISBN: 1-57218-056-0. 